\title{
Considerações sobre a literatura sânscrita \\ Capítulo XVI de Parerga e Paralipomena (Tomo II)
}

\author{
Tradução e notas \\ Rosana Jardim Candeloro \\ Professora da Universidade de Santa Cruz do Sul (UNISC) \\ E-mail: rosanajardimc@gmail.com
}

\section{Considerações sobre a literatura sânscrita ${ }^{4}$}

\section{$\S 183$}

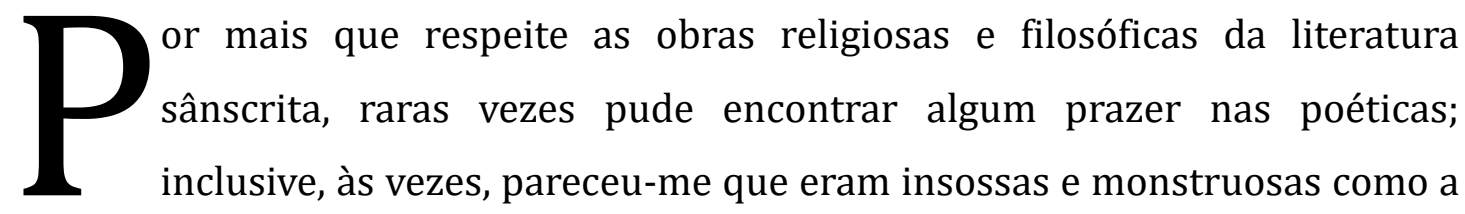
escultura desses mesmos povos. Aprecio ainda suas obras dramáticas principalmente pelas explicações e provas da fé religiosa e dos costumes contidos nelas. Tudo isso se deve ao fato de que a poesia é, por natureza, intraduzível. Nela os pensamentos e as palavras estão tão íntima e firmemente unidos como pars uterina et pars foetalis placenta $^{5}$, de modo que essas não podem ser substituídas por palavras estrangeiras sem afetar àqueles. Embora toda métrica e rima sejam originariamente um compromisso entre o pensamento e a linguagem: ainda assim, por sua natureza, esse compromisso farse-á efetivo apenas no próprio solo materno do pensamento, e não em um estrangeiro ao qual se queira transplantar e menos em um tão estéril como são em geral as mentes tradutoras. E existe por acaso uma oposição maior do que aquela entre a livre fonte de inspiração de um poeta, a qual se revela já por si mesma e instintivamente revestida do metro e da rima, e o penoso, calculista e frio tormento do tradutor, contando sílabas e buscando rimas? Ademais, na Europa não faltam obras poéticas que nos interessem diretamente, mas sim visões metafísicas claras, sinalizo que o tradutor do sânscrito deva

\footnotetext{
${ }^{4}$ Este ensaio consiste no capítulo XVI de P/P, Tomo II. As notas de rodapé são de minha autoria e do editor crítico das obras completas de Arthur Schopenhauer, Prof. Wolfgang von Löhneysen, publicadas em cinco volumes pela Suhrkamp, em 1986, edição utilizada para esta tradução. Quando a nota for do editor crítico, aparecerá, ao final, a inscrição (N.E.).

5 "A parte uterina e a parte fetal da placenta" [a tradução em Alemão, do editor crítico, encontra-se no corpo do texto de Schopenhauer; todavia, para uma melhor visualização, apresento as traduções de citações greco-latinas do texto original em rodapé].
} 
dirigir seus esforços muito menos à poesia e muito mais aos Vedas, às Upanishad e às obras filosóficas.

\section{$\S 184$}

Quando penso quão difícil é, ainda que contando com o apoio dos melhores mestres minuciosamente formados para tal e com excelentes recursos filológicos alcançados no curso dos séculos, atingir uma compreensão correta, precisa e viva dos autores gregos e romanos cujas línguas são as de nossos antepassados europeus e as mães das línguas hoje vivas - e que, não obstante, o sânscrito é uma língua falada há mil anos na Índia e os meios para aprendê-la são relativamente imperfeitos -, quando penso nisso, e acrescento a impressão que me produzem as traduções do sânscrito realizadas por eruditos europeus - deixando à parte poucas exceções -, invade-me a suspeita de que nossos eruditos do sânscrito não são capazes de compreender seus textos melhor que os estudantes de nossas escolas entendem os textos gregos; que, todavia, já que não são meninos, mas, sim, homens de saber e entendimento, com que de fato compreendem a composição do sentido em seu todo, o que alguns poderiam executar ex ingenio $^{6}$. No entanto, pior é o que ocorre com o chinês dos sinólogos europeus, que muitas vezes caem no escuro; disso se convence qualquer um quando vê como até os mais profundos entre eles se corrigem mutuamente e demonstram colossais erros uns para com os outros. Exemplos desse tipo se encontram com frequência no Foe Koue Ki, de Abel Rémusat.

Por outro lado, considerando que o sultão Mahammed Dara Shikoh, irmão de Aurangzeb, nascido e criado na Índia, ali foi educado, refletiu e esteve desejoso de saber, por isso pude compreender seu sânscrito mais ou menos tão bem como nós compreendemos o nosso latim, já que teve um número dos mais sábios Pandits $^{7}$ como colaboradores; tudo isso indica de antemão uma opinião valorosa de sua tradução das Upanishad $^{8}$ dos Vedas para o persa. Outrossim, vejo com que profunda veneração essa

\footnotetext{
${ }^{6}$ Relativo ao uso da capacidade.

${ }^{7}$ Relativo a sábios e eruditos.

8 Conhecidas no Ocidente como Vedanta, a parte final dos Vedas. Sua verdade expressa um entendimento não dual da realidade e indica o caminho do autoconhecimento.

Considerações sobre a literatura sânscrita - Capítulo XVI de Parerga e Paralipomena (Tomo II)
} 
tradução do persa, adequada ao assunto, foi utilizada por Anquetil Duperron ${ }^{9}$ ao reproduzi-la palavra por palavra em latim, mas mantendo exatamente a sintaxe persa a despeito da gramática latina, conservando iguais as palavras sânscritas que o Sultão deixou sem traduzir para explicá-las no glossário; assim que leio essa tradução com a mais plena confiança, logo recebe uma lisonjeira aprovação. Pois como sopra o espírito sagrado dos Vedas através do Oupnekhat ${ }^{10 !}$ Como aquele que, através de uma leitura diligente da tradução persa-latina deste livro incomparável, se familiarizou com o seu conteúdo espantoso e se sentiu possuído por esse espírito no mais íntimo de seu ser! De que maneira cada uma de suas linhas se encontra repleta de significados precisos e poderosos, capazes de penetrar, dando coerência a tudo. Aqui tudo respira ar hindu e uma existência original muito mais afeita à natureza. Através dele, nosso espírito é lavado e purificado de todos os preconceitos judaicos inoculados desde a infância e de toda esta filosofia ocidental, que se deixou escravizar por eles. É a leitura mais gratificante e comovente que possa haver neste mundo (exceto texto original); ela tem sido o consolo de minha vida ${ }^{11}$ e será de minha morte. - Em relação a certas suspeitas alegadas contra a autenticidade do Oupnekhat, remeto à nota da página 271 (v. 3, p. 806) de minha "Ética".

Se comparo as traduções europeias dos textos sagrados ou dos filósofos hindus com essas, produzem-me uma impressão contrária (com poucas exceções, como o Bhagavad-Gita, de Schlegel12, e algumas passagens das traduções dos Vedas, de Colebrooke ${ }^{13}$ ): oferecem períodos cujo sentido é geral e abstrato, com frequência oscilante e impreciso, e cuja conexão é insegura; eu recebo meros contornos dos pensamentos do texto original, com preenchimentos, cuja estranheza eu percebo; também aparecem de vez em quando contradições; tudo é moderno, vazio, solto, plano,

\footnotetext{
${ }^{9}$ Abrahan-Hyacinthe Anquetil-Duperron (1731-1805) foi um linguista francês, que dominava Hebraico, Persa e Árabe. Traduziu, pela primeira vez, o Avesta, escritura zoroástrica

${ }^{10}$ A grafia também pode aparecer como Oupnek ou Oupnek' hat. Schopenhauer teve acesso a essa obra em latim, em dois volumes, na Biblioteca de Weimar. Dos 108 Upanishad, 50 foram contempladas nessa tradução latina. Para uma melhor compreensão das leituras realizadas por ele no período entre $1813 \mathrm{e}$ 1814, recomendo a leitura da dissertação de Mestrado de Fábio Mesquista (Universidade de São Paulo, 2007).

${ }^{11}$ Schopenhauer, ainda vivendo em Weimar na casa de sua mãe, travou um primeiro contato com os manuscritos sagrados da Índia através de Friedrich Majer, em 1814. Majer fora discípulo de Herder e era um expert em questões hinduístas (Cf. SAFRANSKI, Schopenhauer e os anos mais selvagens da Filosofia, 2011).

${ }^{12}$ August W. Schlegel (1767-1845), poeta alemão, crítico literário, tradutor e professor de Sânscrito, verteu a Bhagavad-Gita em 1823.

13 Henry Thomas Colebrooke (1765-1837) foi um orientalista britânico considerado como o primeiro scholar em Sânscrito na Europa. 
pobre de sentido e ocidental: está europeizado, anglicizado, afrancesado ou simplesmente (o que é pior) traduzido em suábio envolto em um nevoeiro ao estilo alemão; quer dizer, ao invés de um sentido claro e definido, oferece meras palavras, mas de forma prolixa; assim, ocorre, por exemplo, com a tradução mais recente de Röer $^{14}$ na Bibliotheca Indica (n. 41, Calcutá, 1853), na qual se reconhece claramente o alemão, que, enquanto tal, está acostumado a redigir períodos nos quais se deixa aos demais a tarefa de pensar algo claro e definido: e com demasiada frequência pode-se perceber também nela algo de foetor judaicus ${ }^{15}$. Tudo isso debilita minha confiança em tais traduções, sobretudo quando considero que os tradutores realizam seus estudos como ganha-pão enquanto o nobre Anquetil Duperron não buscou seu proveito senão impulsionado pelo simples amor à ciência e ao conhecimento, e que o Sultão Dara Shikoh recebeu como recompensa e honorário que lhe cortariam a cabeça por obra de seu irmão imperador, Aurangzeb - in maiorem Dei gloriam ${ }^{16}$. Tenho a firme convicção de que, até agora, apenas no Oupnekhat é possível conseguir um conhecimento real das Upanishad e, portanto, da dogmática verdadeira e esotérica dos Vedas: pode-se ter lido as demais traduções do princípio ao fim sem ter sequer ideia do tema. Também parece que o Sultão Dara Shikoh dispunha de manuscritos sânscritos muito melhores e mais completos que os dos eruditos ingleses.

\section{$\S 185$}

Embora a 'Samhita'17 dos Vedas não possa ser dos mesmos autores da mesma época que as Upanishad, disso nos convencemos plenamente quando lemos o primeiro livro da 'Samhita' do Rigveda'18 traduzida por Rosen ${ }^{19}$ e do 'Sama-Veda'20 por Stevenson 21.

\footnotetext{
14 Eduard Röer publicou em 1859 a Prashna Upanishad na Biblioteca Índica, v. XV, n. 41 e 50, da Asiatic Society of Bengala.

15 Fedor judaico.

16 "para a maior glória de Deus".

17 É um conjunto de ensinamentos provenientes de Shiva.

18 Livro dos Hinos; primeiro volume dos Vedas.

${ }^{19}$ Karl Friedrich Rosen traduziu-o para o alemão em 1830.

20 O Sama Veda é o terceiro livro dos Vedas, mas em termos de relevância litúrgica ele é o segundo mais venerado, depois do Rigveda.

${ }^{21}$ A primeira versão da tradução da 'Samhita', de John Stevenson, é de 1842. Encontrei uma espécie de facsímile de 1924 em um depositório digital (http://wwww.bookdepository.com). No preâmbulo à obra, lê-se: "His book is a reproduction of a book published before 1923. This book may have occasional imperfections such as missing or blurred pages, poor pictures, errant marks etc. that were either part of the original Considerações sobre a literatura sânscrita - Capítulo XVI de Parerga e Paralipomena (Tomo II)
} 
Ambas constam de orações e rituais que respiram um Sabeísmo ${ }^{22}$ cru. Aí, Indra é a suprema divindade invocada e com ela estão o Sol, a Lua, o vento e o fogo. A eles se recitam em todos os hinos as mais servis adulações unidas aos pedidos para vacas, comida, bebida e vitória; e ademais se oferecem sacrifícios. As vítimas e as oferendas dos sacerdotes são as únicas virtudes louvadas. - Dado que Ormuzd (do qual depois surgiu Jeová) é na realidade Indra (segundo Isaak Jakob Schmidt²3) e, além disso, também Mitra é o Sol, a adoração dos ofertantes pelo fogo chegou a eles junto com Indra. - As Upanishad são, como já se disse, o produto da suprema sabedoria humana e também estão destinadas com exclusividade aos sábios brâmanes; por isso, Anquetil traduz Upanishad como secretum tegendum ${ }^{24}$. Em contrapartida, a 'Samhita' é exotérica; é para o povo, embora indiretamente, já que contém a liturgia, isto é, as orações públicas e os rituais das oferendas; em consequência, a 'Samhita' oferece uma leitura de todo insípida 25 , - a julgar pelas provas mencionadas; no entanto, Colebrooke, em seu tratado On the religious ceremonies of the Hindus, traduziu hinos de outros livros da 'Samhita' que exprimiam um espírito afim ao das Upanishad, como é o caso do belo hino no segundo ensaio, "0 espírito encarnado", para o qual forneci uma tradução no $§ 115$ (p. 263f.).

Na época em que se escavaram os grandes templos de rocha na Índia, talvez não houvessem inventado ainda a escrita e os numerosos sacerdotes que neles habitavam fossem os depositários vivos dos Vedas, dos quais cada sacerdote ou cada escola saberia de memória uma parte e a disseminaria; isso é o que fizeram também os druidas ${ }^{26}$. Mais tarde, nesses mesmos templos, isto é, no mais digno entorno, foram redigidas as Upanishad.

artifact, or were introduced by the scanning process. We believe this work is culturally important, and despite the imperfections, have elected to bring it back into print as part of our continuing commitment to the preservation of printed works worldwide. We appreciate your understanding of the imperfections in the preservation process, and hope you enjoy this valuable".

22 Veja p. 448 (N.E.). Os sabeus eram monoteístas e cultuavam o Sol (Almaqah). Viveram em uma região reconhecida como o atual Iêmen. Não se sabe quase nada sobre eles, a não ser que são citados na Bíblia e no Alcorão.

23 Nascido na Holanda, foi um orientalista naturalizado russo.

24 "um segredo que deve ser ocultado" (N.E.).

25 fade (N.E.).

26 Schopenhauer reporta-se aos druidas da sociedade celta, mas não desenvolve sua comparação entre brâmanes e celtas.

Considerações sobre a literatura sânscrita - Capítulo XVI de Parerga e Paralipomena (Tomo II) 
A filosofia do Samkhya, considerada precursora do Budismo, segundo a apreciamos in extenso na Karika de Isvara Krichna ${ }^{27}$,traduzida na íntegra por Wilson ${ }^{28}$ (embora ainda imersa como em neblina, devido à imperfeição dessa mesma tradução), é interessante e instrutiva na medida em que nos apresenta os dogmas principais de toda a filosofia hindu - como a necessidade de serem redimidos de uma triste existência, a transmigração ${ }^{29}$ conforme as ações, o conhecimento como condição principal da salvação etc. - em detalhe e a mais alta seriedade com a qual, desde milênios, se tem tratado esses dogmas na Índia.

Não obstante, vemos que toda a filosofia arruinou-se através de uma falsa ideia fundamental: o dualismo absoluto entre Prakriti e Purusha ${ }^{30}$. Todavia, esse é precisamente o ponto em que a escola Samkhya se desvia dos Vedas. - Está claro que Prakriti é a natura naturans ${ }^{31}$ (e, ao mesmo tempo, a matéria em si, isto é, sem forma, tal como é simplesmente pensada, mas não intuída; esta, assim concebida e na medida em que tudo é gerado dela, pode ser considerada realmente idêntica à natura naturans). Purusha, no entanto, é o sujeito do conhecimento, pois se percebe, é inativo, é um mero espectador. Sem embargo, ambos são tomados como absolutamente distintos e independentes entre si, de modo que a explicação de que Prakriti age pela salvação de Purusha resulta insuficiente (verso 60). Ademais, em toda a obra ensina-se que a finalidade última é a salvação de Purusha: em contrapartida (vv. 62, 63), subitamente, é o Prakriti que precisa ser salvo: todas essas contradições desapareceriam se houvesse uma raiz comum para Prakriti e Purusha, mesmo contra a vontade de Kapila ${ }^{32}$ ou então Purusha seria uma modificação de Prakriti, de modo que o dualismo seria dissolvido. -

\footnotetext{
27 Nos manuscritos sagrados hindus, é a suprema alma.

${ }^{28}$ Horace Hayman Wilson (1786-1860) traduziu um dos textos do Samkhya; em sua versão mais antiga, era chamado de Karika. A tradição do Samkhya (fundada por Kapila) e do Yoga (fundado por Patanjali) não pertence à matriz védico-bramânica, ou seja, não está ligada ao panteão de deuses dos Vedas, mas é próxima à religião jainista.

${ }^{29}$ Seelenwanderung (N.E.).

30 Segundo Zimmer (2003), o universo está alicerçado em uma dicotomia constituída de "mônadas vitais" (Purusha) e de "matéria" inanimada (Prakriti). Cada uma dessas mônadas vitais está associada à matéria cármica e, por sua vez, à roda da transmigração (Samsara).

31 Schaffende Natur (N.E.). Natura naturans, conforme Spinoza, é a natureza criadora.

32 Fundador do sistema Samkhya. Veja v. 4, p. 85 (N.E.). [Kapila significa "vermelho", um epíteto do Sol. É possível que tenha vivido antes da época de Buddha, século VI a. C.].

Considerações sobre a literatura sânscrita - Capítulo XVI de Parerga e Paralipomena (Tomo II)
} 
Para tornar compreensível o assunto, não posso fazer outra coisa senão ver em Prakriti a Vontade e em Purusha, o sujeito do conhecimento.

Uma característica peculiar da estreiteza de visões e do pedantismo da escola Samkhya é a enumeração, o fato de contar e enumerar todas as qualidades etc. Pareceme que é um costume do país, já que nos escritos budistas se faz o mesmo.

O sentido moral da Metempsicose em todas as religiões hindus não é somente que temos de expiar em uma reencarnação seguinte todas as injustiças que cometemos, mas também que devemos considerar toda injustiça que nos fazem como bem merecida por nossos crimes em uma existência anterior.

Pode-se explicar o fato de que as três castas superiores se chamem as renascidas, como usualmente se sugere, porque o investimento no cordão sagrado, que se concede aos jovens, na maioridade, é como um segundo nascimento; mas a verdadeira razão é que somente se nasce naquelas castas como resultado de méritos relevantes em uma vida anterior, de modo que se deve ter existido nela como homem, enquanto que aquele que nasce na casta inferior, ou em uma mais baixa, teve de ser antes um animal.

Ridiculariza-se os Aionen e os Kalpas ${ }^{33}$ do Budismo! - 0 Cristianismo adotou um ponto de vista, a partir do qual ele observa um lapso de tempo; o Budismo adotou outro, a partir do qual a infinitude no tempo e no espaço se lhe representa e torna-se seu tema.

Como os Lalita vistara ${ }^{34}$, em princípio simples e natural, tornaram-se mais complicados e surpreendentes a cada nova redação de que foram alvo em cada um dos concílios, outro tanto ocorreu ao próprio dogma cujas teses escassas, simples e grandiosas foram confundindo, enredando e complicando as explicações detalhadas, as representações espaciais e temporais, as localizações empíricas etc. porque assim a

\footnotetext{
${ }^{33}$ Veja p. 465 (N.E.). [Kalpas são aeons, um longo período de tempo, dentro da cosmologia budista. Mantive as expressões em Sânscrito por não possuir uma alternativa razoável de tradução para o Português].

34 Lalitavistara é um sutra do Budismo Mahayana, que conta a história de Gautama Buddha até o primeiro sermão realizado perto de Varanasi, Índia.
} 
massa aprecia, dando ocupação à fantasia, e não se satisfazendo com o simples e abstrato.

Os dogmas bramânicos e as distinções de Brahm e Brahma, Paramatma e Dschivatma, Hiranya-Garbha, Pradschapati, Purusha, Prakriti etc. (que se encontram muito bem sintetizadas no excelente livro de Obrys $^{35}$, Du Nirvana Indien, 1856) são, no fundo, simples ficções mitológicas criadas com a ideia de representar objetivamente o que, em essência e absolutamente, não tem mais que uma existência subjetiva; por isso Buddha renunciou a elas e não conhece mais que o Samsara e o Nirvana. Pois enquanto mais enredados, confusos e complicados são os dogmas, mais são mitológicos. Quem melhor entende disso são os iogues ou sanyasi36, que, com uma preparação metódica, retraem até seu interior todos os sentidos e esquecem o mundo e a si mesmos: - o que, então, fica em sua consciência é o ser primordial? Isso se diz mais facilmente do que se faz.

A ruína em que se encontra o povo hindu, que outrora teve uma cultura tão elevada, é a consequência da espantosa opressão que sofreu durante 700 anos por parte dos maometanos, que queriam convertê-lo à força ao Islã. - Hoje, somente uma oitava parte da população da Índia é maometana (Edinburg Review, jan. 1858).

\section{$\S 190$}

Entre os indícios de que os egípcios (etíopes), ou ao menos seus sacerdotes, vieram da Índia incluem-se, também, os trechos dos L. III, 20 e L. VI, 11, da Vida de Apolônio de Tiana ${ }^{37}$.

É provável que a mesma relação distante que o Grego e o Latim mantêm com o Sânscrito tenha também a mitologia dos gregos e romanos com a dos hindus e a egípcia. 0 copra ${ }^{38}$ é derivado da matriz jafética ou do semítico? Zeus, Posêidon e Hades são talvez

\footnotetext{
${ }^{35}$ Jean Baptiste François Obry publicou seu livro Du Nirvana Indien em 1856. Para maiores esclarecimentos sobre as leituras que fez Schopenhauer de manuscritos hindus, acessar HÜBSCHER, A., em: $<$ www.schopenhauer.philosophie.uni-mainz.de>.

${ }^{36}$ Os sanyasi, na Índia e no Nepal, são as pessoas que renunciam aos seus bens materiais para viver nos templos, cavernas ou florestas.

${ }^{37}$ Atribui-se esta obra a Flávio Filóstrato. Apolônio era um neopitagórico, nascido em Tiana, na Ásia Menor, atual Capadócia, na Turquia.

38 Também chamados de coptas. Eram os cristãos que viviam no Egito. 0 copra ou copta é uma língua que floresceu no Antigo Egito por volta do século III, da família linguística camito-semítica.

Considerações sobre a literatura sânscrita - Capítulo XVI de Parerga e Paralipomena (Tomo II)
} 
Brahma, Vishnu e Shiva39; essa última tem um tridente cuja finalidade não está clara em Posêidon. A chave do Nilo, crux ansata ${ }^{40}$, símbolo de Vênus, é exatamente Lingam e Yoni dos shivaístas. Osiris ou Isiris é talvez Isvara, Senhor e Deus. O lótus é reverenciado tanto por egípcios quanto hindus.

Não deveria Jano ${ }^{41}$ (sobre o qual Schelling ${ }^{42}$ acaba de ministrar uma conferência acadêmica em que o considera um uno originário) ser Yama, o Deus da Morte, que tem dois rostos e, às vezes, quatro? Em tempos de guerra, as portas da morte estão abertas. E quem sabe Pradschapati não seria Jápeto?

A deusa Anna Purna dos hindus (Langlès, 'Monuments de l’Inde', v. 2, p. 107) é, seguramente, a Ana Perena ${ }^{43}$ dos romanos. - Baghis, um sobrenome de Shiva, relembra o vidente Bakis (Ib., v. 1, p. 178). No 'Sakontala'44 (ato 6, conclusão, p. 131), aparece Divespetir como sobrenome de Indra: aparentemente, Diespiter 45 (Júpiter).

Em favor da identidade de Buddha com Wodan ${ }^{46}$, fala-se do fato de que (segundo Langlès ${ }^{47}$, Monuments, v. 2), a quarta-feira (Wodansday) é sagrada para Mercúrio e para

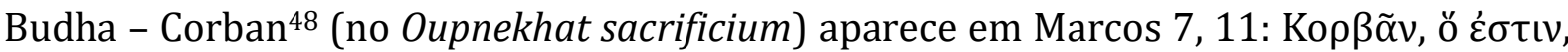
$\Delta \tilde{\omega} \rho o v$, em latim: Corban, munus Deo dicatum (Corban, isto é, oferenda). - 0 mais importante de tudo é o seguinte: o planeta Mercúrio é sagrado para Buddha; é, relativamente, identificado com ele e a quarta-feira é o dia de Buddha. Mercúrio, todavia, é filho de Maya, e Buddha, da Rainha Maya. Isso não pode ser uma coincidência! Aqui, dizem os suábios, "há um menestrel enterrado!" (Conferir no Manual of Buddhism, p. 354, nota, e Asiatic Researches, v. 1, p. 162).

Spence Hardy ${ }^{49}$ (On Eastern Monachism, p. 122) informa que, para uma

\footnotetext{
${ }^{39}$ Brahma, Vishnu e Shiva constituem a trimúrti, a tríade das deidades hindus. As adorações a Vishnu chamam-se Vishinuísmo e à Shiva, Shivaísmo.

${ }^{40} \mathrm{~A}$ cruz ansata era um atributo das deidades egípcias (N.E.). [A cruz ansata, Ankh, era o símbolo da vida eterna nos hieróglifos egípcios].

${ }^{41}$ Janus, na cultura romana, era representado com duas faces.

${ }^{42}$ Schelling oferece uma explicação de Jano (na academia de Berlim) na qual ele significa "o caos na unidade originária". - Uma explicação muito mais fundamentada é a que oferece Walz em De Religione Romanorum antiquissima (no programa da Universidade de Tübingen), 1845 (N.E.).

${ }^{43}$ Segundo a mitologia, Ana Perena era uma deusa de Roma, símbolo da abundância e do alimento.

${ }^{44}$ Sacontalá é um drama indiano, escrito por Cálidás e traduzido por Sir William Jones (1789).

${ }^{45}$ Nas já citadas Asiatic Researches, v. I, p. 241 (N.E.).

${ }^{46}$ Na mitologia germânica, Wodan, Wotan, Woden ou Wuotan é Odin.

${ }^{47}$ Louis-Mathieu Langlès (1763-1824) foi um linguista e orientalista francês. Não encontrei dados sobre a obra Monuments, indicada por Schopenhauer.

${ }^{48}$ Esta palavra aramaica foi inserida no texto em Sânscrito (N.E.).

${ }^{49}$ Robert Spence Hardy (1803-1868) publicou a obra comentada por Schopenhauer em 1860. Todas as suas publicações podem ser acessadas na Hathi Trust Digital Library, em: $<$ http://www.babel.hathitrust.org >.

Considerações sobre a literatura sânscrita - Capítulo XVI de Parerga e Paralipomena (Tomo II)
} 
determinada festividade, tinha-se de confeccionar em um dia os trajes que precisavam ser enviados aos sacerdotes ${ }^{50}$ : o mesmo disse Heródoto (Historiae, II, 122), com relação às vestimentas que haveriam de ser entregues a um sacerdote em uma ocasião solene.

0 autóctone dos alemães é Mannus e seu filho é Thuiskon; no 'Oupnekhat' (v. 2, p. 347 e v. 1, p. 96), o primeiro homem chama-se Man.

Sabe-se que Satyavrati é idêntico a Menu ou Manu - como, em outros lugares, a Noé. O pai de Sansão, entretanto, chamava-se Manoe - também Manu, Noah (Noé) (Livro dos Juízes, cap. 13); a Septuaginta escreve M $\alpha v \omega \varepsilon$. Seria Noé diretamente Manoe, sem a primeira sílaba?

Entre os etruscos, Júpiter chamava-se Tina (Moreau, 'De Jonès', Academia de Ciências Morais e Políticas, dez. 1850). Isso tem relação com o Tien chinês? Os etruscos tinham a Ana Perena dos hindus.

Todas essas analogias foram pesquisadas a fundo por Wilford 51 e von Burr ${ }^{52}$ nas Asiatic Researches.

\section{Referências bibliográficas}

HARDY, R. S. Complete Works. Disponível em: <http://www.babel.hathitrust.org>. Acesso em: 15 mar. 2015.

HÜBSCHER, A. Schopenhauer und die Religionen Asiens. Frankfurt a/M. Disponível em: <schopenhauer .philosophie.uni-mainz.de. S. Eastern Monachism. Williams and Norgate: London/Edinburg, 1860 (arquivo digitalizado pela University of Minnesota, EUA). Disponível em: <http://www.catalog.hathitrust.org>. Acesso em: 28 dez. 2015.

MESQUITA, F. L. de A. Schopenhauer e o Oriente. Programa de Pós-graduação em Filosofia da Universidade de São Paulo, 2007. [Dissertação de Mestrado].

SAFRANSKI, Rüdiger. Schopenhauer e os anos mais selvagens da Filosofia: uma biografia. Trad. William Lagos. São Paulo: Geração Editorial, 2011.

SCHOPENHAUER, A. Parerga und Paralipomena. In: __. Sämtliche Werke. Textkritisch bearbeitet und herausgegeben von Wolfgang von Löhneysen. Stuttgart/Frankfurt am Main: Suhrkamp, 1986. 5 Vol.

SACONTALÁ. Disponível em: <http://www.cmadras.com>. Acesso em: 20 set. 2013.

STEVENSON, J. Translation of the Sanhitá of the Sáma Veda. Charleston: Nabu Press, s. d. Disponível em: <http//: www.bookdepository.com>. Acesso em: 12 ago. 2013.

ZIMMER, H. Filosofias na Índia. Compilação de Joseph Campbell. Tradução de Nilton Almeida Silva, Cláudia Giovani Bozza e Adriana Facchini de Cesare. Versão final de Lia Diskin. 5. ed. rev. ampl. São Paulo: Palas Athena, 2012.

500 trecho original de Hardy, à p. 122 é: [... "The Egytian priests in one day when they observed the festival in memory of Rampsinitus from the infernal regions". (HATHI TRUST DIGITAL LIBRARY, $<$ http://ww.hathitrust.org $>$ ).

51 Francis Wilford (1761-1822) foi um orientalista, membro da Sociedade Asiática de Bengala, Índia. 52 Não encontrei informações confiáveis sobre este tradutor e orientalista mencionado por Schopenhauer.

Considerações sobre a literatura sânscrita - Capítulo XVI de Parerga e Paralipomena (Tomo II) 
Recebido: 13/07/16 Received: 07/13/16

Aprovado: 04/11/16 Approved: 11/04/16 